Article

\title{
Optimal Replenishment Policy for Deteriorating Products in a Newsboy Problem with Multiple Just-in-Time Deliveries
}

\author{
Abu Hashan Md Mashud ${ }^{1}$, Hui-Ming Wee ${ }^{2, *} \mathbb{C}$, Chiao-Ven Huang ${ }^{2}$ and Jei-Zheng $\mathrm{Wu}^{3, *,+}$ (i) \\ 1 Department of Mathematics, Hajee Mohammad Danesh Science and Technology University, \\ Dinajpur 5200, Bangladesh; mashud@hstu.ac.bd \\ 2 Department of Industrial and Systems Engineering, Chung Yuan Christian University, \\ Chungli 32023, Taiwan; jackjcv@yahoo.com.tw \\ 3 Department of Business Administration, Soochow University, 56 Section 1, Kuei-yang Street, Taipei 10048, Taiwan \\ * Correspondence: weehm@cycu.edu.tw (H.-M.W.); jzwu@scu.edu.tw (J.-Z.W.); \\ Tel.: +886-3265-4409 (H.-M.W.); +886-2311-1531 (J.-Z.W.) \\ $+\quad$ If you are interested or have any doubt of this article, please contact Jei-Zheng Wu (jzwu@scu.edu.tw) first.
}

Received: 4 October 2020; Accepted: 22 October 2020; Published: 6 November 2020

\begin{abstract}
Product deterioration is a common phenomenon and is overlooked in most contemporary research on the newsboy problem. In this study, we have considered product deterioration in a production-inventory newsboy model based on multiple just-in-time (JIT) deliveries. This model is solved by a classical optimization technique for the manufacturer production size, wholesale price, replenishment plan, and retailer order policy using a distribution-free approach. Moreover, in order to improve business and entice more customers, a return policy and a post-sale warranty policy is adopted in the model. Theoretical development and numerical examples are provided to demonstrate the validity of this approach.
\end{abstract}

Keywords: production inventory; newsboy model; deteriorating items; distribution free

\section{Introduction}

Demand is considered a crucial attribute in inventory research in the present competitive and transparent business. The uncertain product demand is an important factor in products with a short life cycle. For instance, some apparel goods, some electronic devices (e.g., computers, mobile phones, TVs, fridges, etc.), and some food items have uncertain demand as well as short life cycles. Predicting demand accurately is critical in satisfying customer demand. However, in every business, the retailer may face shortages or overstocking problems due to this inaccurate demand prediction; this leads to a loss of business. In order to deal with the uncertain demand problem, a newsboy model which considers the stochastic or exogenous demand is used. For products with stochastic demand, retailers usually adopt newsboy models to determine the optimal ordering decisions. In recent years, variable demand [1], fuzzy demand [2], and price-sensitive demand [3] have received more attention by researchers. The newsboy problem is a classical inventory problem that is worth studying from both theoretical and practical perspectives [4,5]. It is generally applicable for decision making in the apparel and sporting equipment industries [6-8]. In this study, we address the distribution-free newsboy problem [9].

Deterioration is a common phenomenon for most products. For instance, food items, vegetables, electronics items, etc., deteriorate over time. A synergy between product deterioration and demand has been studied. For uncertain demand and high deterioration rate, inventory management has become more difficult for the retailer. When demand is known, it is easier for a retailer to manage deteriorating items. Hence, an important question is how to deal with deteriorating items with uncertain demand. 
In our model, we proposed a newsboy model considering product deterioration and uncertain demand. The study can provide some managerial insights for products with the mentioned characteristics.

The primary goal of this study is to develop a strategy to derive an optimal production size when the wholesale price is known. We have taken into consideration how the wholesale price and post-sale warranty influence production size and the material replenishment policy. Various integrated inventory models considering return policies for retailers have been developed due to imperfect products in a production process, e.g., failure of the machine, unskilled labor, and bad weather [2]. Our study considers deteriorating items for the newsboy problem and proposes an integrated retailer-manufacturer inventory model. Some of the major contributions of the study are:

- We derive the optimal wholesale price and production strategies for a newsboy problem model.

- We incorporate product deterioration into the newsboy problem model.

- We simultaneously include repair cost, warranty cost, setup cost, item cost, storage cost, and JIT delivery.

The remainder of this study is structured as follows: The literature review is provided in Section 1.1. The problem description, notation, and assumptions are presented in Section 2. Section 3 introduces model descriptions and mathematical formulations. In Section 4, the optimization technique and its algorithm are discussed. Numerical examples are given in Section 5. Finally, Section 6 provides managerial insights, conclusions, and suggestions for future studies.

\subsection{Literature Review}

Deterioration of products is a crucial factor in today's competitive and transparent business. Deterioration is the decay, spoilage, obsolesce, or evaporation of products which degrade the quality and quantity of the products [10-13]. Ghare and Schrader [14] were the first authors to introduce a deteriorating inventory model. Later, Covert and Philip [15] and Raafat et al. [16] developed the concept of product deterioration under various assumptions. Wee [17] proposed a production inventory model with partial backlogged shortages, and Mashud et al. [10] considered different types of deterioration with shortages. Wee and Jong [18] examined the just-in-time (JIT) delivery strategy for deteriorating items in an integrated production-inventory model, while Perez and Torres [19] developed a multiple-delivery inventory model. Their models considered product deterioration and the time value of money with JIT delivery. Yang and Wee [20] developed an inventory model for deteriorating items based on a production model for multiple lot-sizing problems. By incorporating pricing strategies into a single-period supply chain with return policies, Lau and Lau [21] have studied the effect of uncertain demand in the retail market on retailers' and manufacturers' estimated profits. Lariviere and Porteus [22] incorporated market size and growth into a model to investigate how these two attributes affect profits. Abdel and Ziegler [23] recommended a two-echelon inventory model without shortage. This approach features variable holding costs with fixed demand for a perishable item for multi-echelon supply chains. In the models, the Lagrange function is applied to obtain the optimal order quantity for manufacturers and retailers. Yoo et al. [24] introduced a model for imperfect items under a return policy, and Sarkar et al. [25] provided a remanufacturing and returnable model for a closed-loop supply chain. Eppen [26] proposed a model of $\mathrm{N}$ locations with normal distribution demand with a penalty cost. Chang and Lin [27] modified Eppen's model by incorporating transportation cost; their results indicated that the projected holding and penalty costs were higher under decentralized coordination than under centralized coordination. However, for most cases, centralized coordination is preferable to decentralized coordination due to lesser overall costs [28]. According to Cherikh [28], the excess demand is distributed to other locations due to a stock-out situation, while this proposed model does not allow any stock-out situations through some continuous reviews of inventories. Another important contribution that stemmed from Cherikh [28] is that the model considers multi-locations in the newsboy problem, while this proposed model considers a multi-player newsboy model. 
The effect of different demand patterns has impacted the distribution-free newsboy problem where the demand distribution is unknown. Some studies have investigated the distribution-free newsboy problem with the mean $(\mu)$ and variance $\left(\sigma^{2}\right)$. Gallego and Moon [6] explored the circumstances for constrained multiple products with random yields and constant ordering costs. Numerous researchers have indicated that demand behaves exogenously for varying demand atmospheres [21,29-34]. For instance, if one plugs the trade credit approach in the model then it will trigger the demand for a certain period, which is known as exogenous behavior of demand.

Quality management and manufacturing strategy are primary manufacturing concerns. JIT delivery is a manufacturing methodology in which quality management and manufacturing strategy are incorporated into the overall organizational function. Sakakibara et al. [35] investigated the influence of JIT manufacturing and infrastructure on manufacturing performance. They found that quality management, manufacturing strategy, and workforce management are critical in business competitiveness. Quality management, manufacturing strategy, and purchasing are closely linked in JIT manufacturing. Nassimbeni [36] identified three factors correlated to purchasing, namely synchronization, interaction, and design. To avoid potential production disruptions and wastage, and to ensure quality and quick recovery, small deliveries should be implemented alongside appropriate production-inventory strategies [37,38]. In production-inventory strategies, another important factor which has been discussed recently is the sustainability of the economic growth, which mainly depends on numerous parameters [39-42]. Kung et al. [43] considered a production-inventory system for deteriorating items with machine breakdown, inspection, and partial backordering.

Due to the possible defective products as a result of an imperfect production process [44-48], the company may provide a product warranty; the warranty costs are influenced by the product quality and price. Daryanto and Wee [49] were among the first authors to investigate the joint effect of imperfect production for deteriorating items, and Shaw et al. [50] developed an inventory model for repairable deteriorating items. Hasan et al. [51] considered an imperfect production system for deteriorating agricultural products where product separation is conducted to segregate perfect ones from defective ones. Yeh et al. [52] considered a free warranty service in their production-inventory model, and Wang and Sheu [53] converted this free warranty process into a discrete unit for an imperfect production system. Both of these models minimized the optimal production lot size, and the total supply chain cost. Moreover, Wang [54] developed a production model with a free warranty period and Lin [55] studied the effects of warranty and quantity discounts for deteriorating items with allowable shortages. Ullah et al. [56] investigated the newsboy problem with a discount policy under various pricing strategies. However, from our literature search, few studies have developed a newsboy problem model for deteriorating items with an imperfect process.

\section{Problem Description, Assumptions, and Notation}

In this section, the problem description of the proposed study is introduced along with the associated assumptions and notation.

\subsection{Problem Description}

In the proposed production-inventory model (PIM), there are $M$-types of raw material in the manufacturing process (Figure 1). The finished product must be delivered to the retailer before the expiration date. After the expiration date, the products must be discharged at a salvage value. 


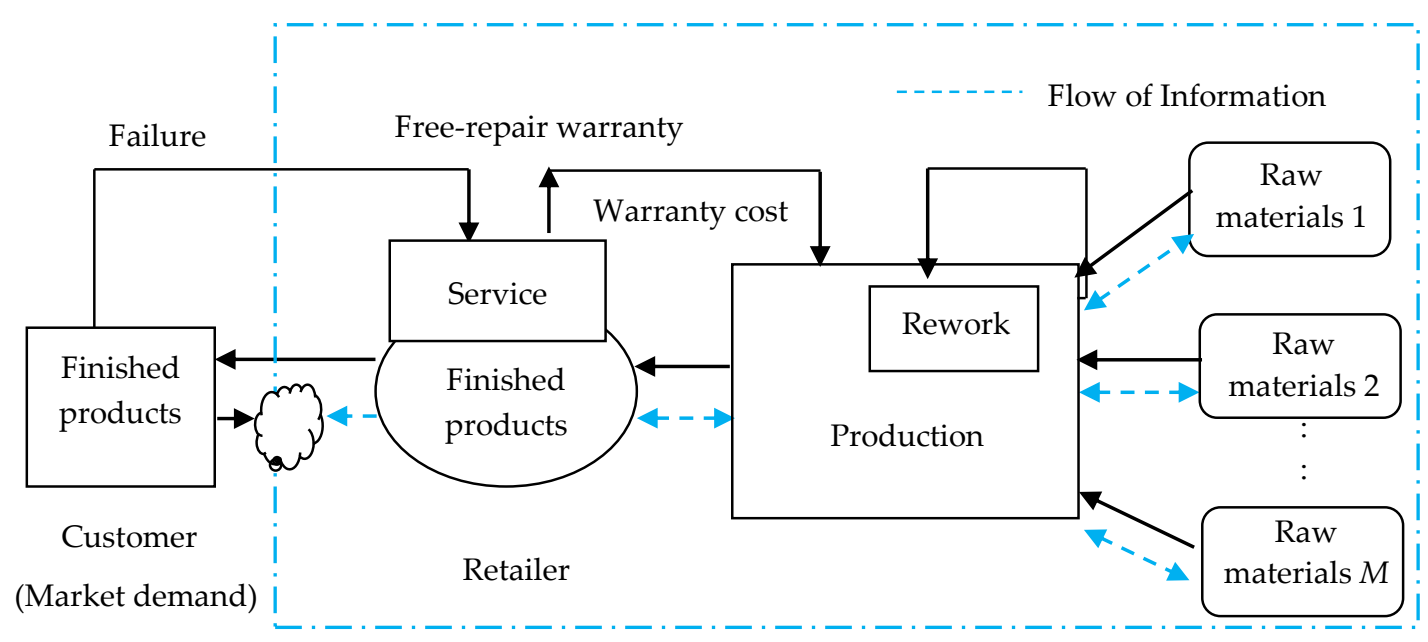

Figure 1. Schematic of the production-inventory model with various activities. Source: modified from [57].

The retailer can make ordering decisions, but price is not under their control. In our model, the retailer's ordering costs are considered to be proportional to the ordering capacity, which affects the logistics cost. Different from previous studies, our model considers free repair or replacement by the manufacturer for defective items, as well as the manufacturer's repair cost, warranty cost, and JIT benefit.

The study is divided into two phases. Phase 1 is related to the retailer's order strategy and phase 2 focuses on the manufacturer's strategy and associated circumstances.

\subsection{Assumptions}

The following assumptions are adopted to formulate the problem:

a. Total orders are calculated by the manufacturer based on the retailer's orders according to the production lot size for the following cycle while the demand is considered unknown.

b. Material inventory is controlled through periodic reviews; backlogging is forbidden to prevent shortages.

c. A static wholesale price is set by the manufacturer during replenishment, and the newsboy rule is followed by the retailer to regulate the order quantity with reference to the average demand, total salvage cost, and wholesale price.

d. The lead-time for raw materials is fixed, and the transportation time is considered to be zero.

e. The production rate is larger than the demand rate.

f. The deterioration rate is constant, and the deterioration rate is considered only after the product has been received into inventory.

g. No information gaps are considered during negotiations.

h. Replenishment is instantaneous.

i. The production procedure is initially controlled; after intervention, it may vary between controlled and out of control. The intervention time imperfect production process is distributed exponentially with known mean and variance.

j. Imperfect production is not identified until the completion of an inspection process.

k. JIT production and JIT multiple-delivery strategies are considered.

\subsection{Notations}

Table 1 presents the notations used in the model. 
Table 1. Notations.

\begin{tabular}{|c|c|c|c|}
\hline$\mu_{c}$ & The mean demand & $\vartheta_{1}$ & $\begin{array}{l}\text { Ratio of non-conforming products when the } \\
\text { procedure is under control }\end{array}$ \\
\hline$\sigma$ & Standard deviation parameter & $\vartheta_{2}$ & $\begin{array}{l}\text { Ratio of non-conforming products when the } \\
\text { procedure is out of control }\end{array}$ \\
\hline$S=\left(1+L_{1}\right) C_{p}$ & Retailer's selling price of products & $C_{R}$ & Per unit cost for rework procedure \\
\hline$L_{s}=L_{2} C_{p}$ & Per unit value of lost sale amount & $C_{w}$ & Per unit cost for item warranty \\
\hline$V=\left(1-L_{3}\right) C_{p}$ & Per unit value of salvage amount & $G_{m}$ & Per unit target profit \\
\hline$C_{r j}$ & Item cost of material $j$ per unit & $u$ & Per unit item production cost \\
\hline$U=L_{4} C_{p}$ & Per unit transportation cost & $H$ & Per unit holding cost for manufacturer \\
\hline$A_{1}=L_{5} C_{p}$ & Per unit ordering items cost & $L_{j}^{1}$ & $\begin{array}{l}\text { The variation of lead-time for material } j \\
\text { (=maximum lead-time -average lead-time) }\end{array}$ \\
\hline$C_{S}$ & Cost of setup for production & $C_{m j}$ & Ordering cost for material $j$ \\
\hline$P$ & Production rate & $h_{d m j}$ & Additional cost to handle the material $j$ \\
\hline$\Theta$ & Rate of deterioration & $h_{d m j}$ & Additional cost to handle the material $\mathrm{j}$ \\
\hline K & Duration of warranty & $H_{r j}$ & Holding cost for materials \\
\hline$A_{0}$ & Constant ordering cost & $\alpha_{j}$ & Quantity of material $j$ required per unit product \\
\hline$F$ & Constant transportation cost & $r_{j}$ & The decrease fraction for material $j$ \\
\hline$C_{p}$ & Per unit purchase cost & $L_{1}$ & Constant coefficient of selling price \\
\hline$L_{2}$ & Constant coefficient of lost sale amount & $L_{3}$ & Constant coefficient of salvage amount \\
\hline$L_{4}$ & Constant coefficient of transportation cost & $L_{5}$ & Constant coefficient of ordering cost \\
\hline
\end{tabular}

\section{Model Development}

The mathematical form of the proposed model is presented in Section 3.1 along with some associated lemmas to support the applicability of the model. In Section 3.2, the cost for the manufacturer is provided along with the respective cost function. Finally, the material cost for the manufacturer is provided in Section 3.3.

\subsection{Mathematical Form of the Model}

Demand is primarily affected by wholesale price in most practical cases, and this is the most critical factor for decision making when considering ordering a new product. Moreover, demand is usually unknown for seasonal products because of the unknown wholesale price. The distribution-free approach can be adopted to investigate this problem. The primary aim of this study was to develop a distribution-free approach for a two-echelon PIM. We assumed that demand follows the worst possible distribution, $\mathfrak{J}$ and an unknown distribution is denoted by $G$. Let $D^{R}$ represent the random demand $G \in \mathfrak{I}$ with mean $\mu$ and variance $\sigma^{2}$.

To determine the optimal ordering quantities, the following relations can be derived:

$$
\begin{gathered}
S=\left(1+L_{1}\right) C_{P}, 0<L_{1}<1 \\
V=\left(1-L_{3}\right) C_{P}, 0<L_{3}<1 ; \\
L_{S}=L_{2} C_{P}, 0<L_{2}<1 ; \\
U=L_{4} C_{P}, 0<L_{4}<1 ; \\
A_{1}=L_{5} C_{P}, 0<L_{5}<1 .
\end{gathered}
$$

The retailer determines the order quantity based on the newsboy policy; the order quantity $\left(Q^{N}\right)$ fulfills the following formula:

$$
E R^{G}=S E\left(\min \left\{Q^{N}, D^{R}\right\}\right)+V E\left(Q^{N}-D^{R}\right)^{+}
$$




$$
\begin{gathered}
E C^{G}=A_{0}+F+\left(A_{1}+C_{P}+U\right) Q^{N}+L_{S} E\left(D^{R}-Q^{N}\right)^{+} \\
E P^{G}=E R^{G}-E C^{G}
\end{gathered}
$$

Equation (2) can be restated by substituting the following equations:

$$
\begin{gathered}
E\left(\min \left\{Q^{N}, D^{R}\right\}\right)=D^{R}-\left(D^{R}-Q^{N}\right)^{+} \\
\left(D^{R}-Q^{N}\right)^{+}=\left(D^{R}-Q^{N}\right)+\left(Q^{N}-D^{R}\right)^{+} \\
\left(Q^{N}-D^{R}\right)^{+}=\left(Q^{N}-D^{R}\right)+\left(D^{R}-Q^{N}\right)^{+}
\end{gathered}
$$

Thus, Equation (2) becomes:

$$
\begin{aligned}
& E R^{G}=S \mu-S E\left(D^{R}-Q^{N}\right)^{+}+V E\left(Q^{N}-D^{R}\right)^{+}-\left\{A_{0}+F+\left(A_{1}+C_{P}+U\right) Q^{N}+L_{S} E\left(D^{R}-Q^{N}\right)^{+}\right\} \\
& E P^{G}=C_{P}\left\{\left(L_{1}+L_{3}-L_{2}\right) \mu-\left(L_{1}+L_{3}\right) E\left(D^{R}-Q^{N}\right)^{+}-\left(L_{3}-L_{2}-L_{4}-L_{5}\right) Q^{N}-\left(L_{2}\right) E\left(Q^{N}-D^{R}\right)^{+}\right\}-A_{1}-F
\end{aligned}
$$

To maximize Equation (3), the following lemmas developed by Gallego and Moon [6] are applied.

In lemmas 1 and 2, they presented a very compact optimality proof of Scarf's ordering rule for the newsboy problem where only the mean and the variance of the demand are known.

\section{Lemma 1.}

$$
E\left(D^{R}-Q^{N}\right)^{+} \leq \frac{\left(\left[\sigma^{2}+\left(Q^{N}-\mu_{c}\right)^{2}\right]^{\frac{1}{2}}-\left(Q^{N}-\mu_{c}\right)\right)}{2}
$$

\section{Lemma 2.}

$$
E\left(Q^{N}-D^{R}\right)^{+} \leq \frac{\left(\left[\sigma^{2}+\left(\mu_{c}-Q^{N}\right)^{2}\right]^{\frac{1}{2}}-\left(\mu_{c}-Q^{N}\right)\right)}{2}
$$

Equation (3) can be revised using lemmas 1 and 2 as follows:

$$
\begin{aligned}
E P^{G} & \geq C_{P}\left\{\left(L_{1}+L_{3}-L_{2}\right) \mu-\left(L_{1}+L_{3}\right) \frac{\left[\sigma^{2}+\left(Q^{N}-\mu_{c}\right)^{2}\right]^{1 / 2}-\left(Q^{N}-\mu_{c}\right)}{2}\right. \\
& \left.-\left(L_{3}-L_{2}-L_{4}-L_{5}\right) Q^{N}-\left(L_{2}\right) \frac{\left[\sigma^{2}+\left(\mu_{c}-Q^{N}\right)^{2}\right]^{1 / 2}-\left(\mu_{c}-Q^{N}\right)}{2}\right\}-A_{1}-F
\end{aligned}
$$

We then maximize the lower bound of Equation (4) by minimizing the following function:

$$
\begin{aligned}
& \Theta E p^{G}=\left\{\left(L_{3}-L_{2}-L_{4}-L_{5}\right) Q^{N}+\left(L_{1}+L_{3}\right) \frac{\left[\sigma^{2}+\left(Q^{N}-\mu_{c}\right)^{2}\right]^{1 / 2}-\left(Q^{N}-\mu_{c}\right)}{2}\right. \\
& \left.+\left(L_{2}\right) \frac{\left[\sigma^{2}+\left(\mu_{c}-Q^{N}\right)^{2}\right]^{1 / 2}-\left(\mu_{c}-Q^{N}\right)}{2}\right\} \\
& =\frac{1}{2}\left\{\left(L_{3}-L_{2}-L_{1}-2\left(L_{4}+L_{5}\right)\right) Q^{N}+\left(L_{3}+L_{2}+L_{1}\right)\left[\sigma^{2}+\left(Q^{N}-\mu_{c}\right)^{2}\right]^{1 / 2}+\left(L_{3}-L_{2}+L_{1}\right) \mu_{c}\right\}
\end{aligned}
$$


The wholesale price influences the ordering decision. Therefore, we take the first derivative of $\Theta E p^{G}$ with respect to $Q^{N}$ and set it equal to zero; after deterioration is taken into consideration, the result is:

$$
Q^{N *}=\frac{1}{1-\theta}\left\{\mu_{c}+\frac{\sigma(R / Z)}{\left[1-(R / Z)^{2}\right]^{1 / 2}}\right\}
$$

where $\frac{R}{Z}=\frac{L_{3}-L_{2}-L_{1}-2\left(L_{4}+L_{5}\right)}{L_{3}+L_{2}+L_{1}}$

\subsection{Manufacturing Cost}

According to Figure 2, the following differential equation represents the inventory level during the manufacturer's production period:

$$
\frac{d \Psi_{S}\left(t_{1}\right)}{d t_{1}}=P-\theta \cdot \Psi_{S}\left(t_{1}\right) 0 \leq t_{1} \leq T_{p}
$$

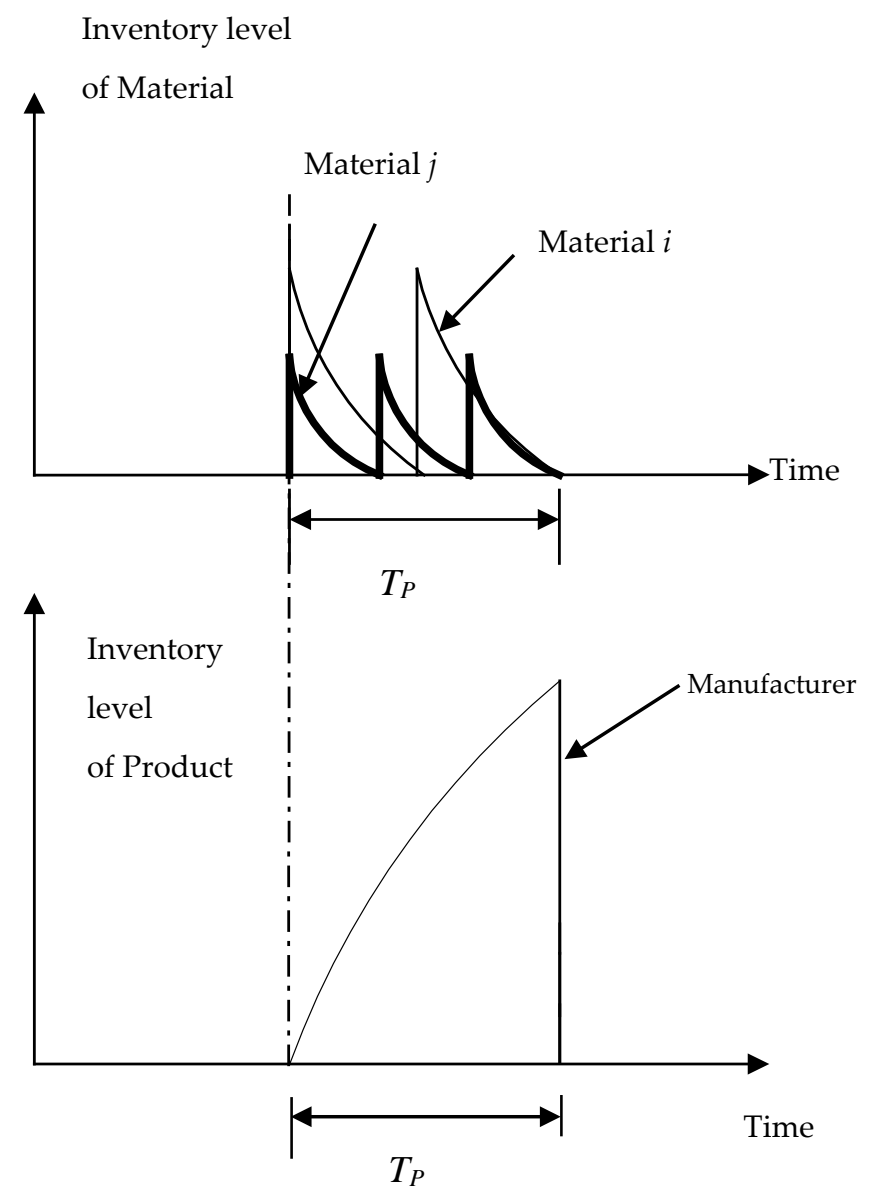

Figure 2. Manufacturer inventory system for deteriorating items in a single-period production-inventory model (PIM).

Given the boundary conditions $\Psi_{S}(0)=0$ and $\Psi_{S}\left(T_{P}\right)=Q^{N_{v}}$ [58], the solution of Equation (6) can be written as follows:

$$
\begin{gathered}
\Psi_{S}\left(t_{1}\right)=\frac{P}{\theta}\left\{1-e^{-\theta t_{1}}\right\} \\
\Psi_{S}\left(T_{p}\right)=Q_{v}^{N}=\frac{P}{\theta}\left\{1-e^{-\theta T_{p}}\right\}
\end{gathered}
$$


Because $\theta<<1$ and $T_{P}<1, e^{-\theta T_{p}}$ can be replaced by $1-\theta T_{P}+\frac{1}{2 !}\left(\theta T_{P}\right)^{2}$. The fraction error for the third term in the Taylor series is given by

$$
\frac{\frac{1}{2 !}\left(\theta T_{P}\right)^{2}}{1-\theta T_{P}+\frac{1}{2 !}\left(\theta T_{P}\right)^{2}}
$$

When $\theta T_{P} \leq 0.03$, the error is approximately $0.0464 \%$. The error is negligible for terms higher than the third order in the Taylor series.

Next, the Taylor expansion can be used to estimate $Q_{v}^{N}$ :

$$
\frac{P}{\theta}\left\{\theta T_{P}-\frac{\left(\theta \cdot T_{P}\right)^{2}}{2}\right\}=Q_{v}^{N_{v}}
$$

From Equations (7) and (8), when the order quantities of the manufacturer and retailer are connected by setting $Q^{N} v=Q^{N *}$ and letting $Q^{N *}=Q^{N} /(1-\theta)$, the time required to complete production is determined as follows:

$$
T_{P}=\frac{1-\sqrt{1-\frac{2 \theta Q^{N^{*}}}{P}}}{\theta}=\frac{1-\sqrt{1-\frac{2 \theta Q^{N}}{P(1-\theta)}}}{\theta}
$$

Proposition 1. When the deterioration rate tends to zero, $T_{P} \rightarrow \frac{Q^{N}}{P}$.

The proof of this proposition is provided in Appendix A.

Considering the deterioration rate, the manufacturer's storage cost is

$$
\begin{aligned}
& H \int_{0}^{T_{P}} \Psi_{S}\left(t_{1}\right) d t_{1}=H \int_{0}^{T_{P}} \frac{P}{\theta}\left\{1-e^{-\theta t_{1}}\right\} \\
& =\frac{H P\left[\theta T_{P}-1+e^{-\theta T_{p}}\right]}{\theta^{2}} \approx \frac{H P T_{P}^{2}}{2}\left(1-\frac{\theta T_{P}}{3}\right)
\end{aligned}
$$

Because the production process is imperfect, the occurrence time is assumed to be exponentially distributed with a mean of $1 / \mu$; that is,

$$
f(\chi)=\mu e^{-\mu \chi} \text { and } 1-F(\chi)=e^{-\mu \chi}
$$

The number of the nonconforming items $\phi$ is obtained from the following relation with the production time.

$$
\phi=\left\{\begin{array}{lr}
\vartheta_{1} P T_{P}, & \text { when } \chi \geq T_{P} \\
\vartheta_{1} P \chi+\vartheta_{2} P\left(T_{P}-\chi\right), & \text { when } \chi<T_{P}
\end{array}\right.
$$

Because $\mu$ is extremely small, according to Equation (11), the expected number of nonconforming products is

$$
\begin{aligned}
E(\phi) & =\left\{\int_{0}^{T_{P}}\left[\vartheta_{1} P \chi+\vartheta_{2} P\left(T_{P}-\chi\right)\right] f(\chi) d \chi+\vartheta_{1} P \int_{T_{P}}^{\infty} T_{P} f(\chi) d \chi\right\} \\
& =\left\{\left(\vartheta_{2} P T_{P}+\left(\vartheta_{1}-\vartheta_{2}\right) P \int_{0}^{T_{P}} e^{-\mu X} d \chi\right)\right\} \\
& =\left\{\left(\vartheta_{2} P T_{P}+\left(\vartheta_{1}-\vartheta_{2}\right) P \int_{0}^{T_{P}}\left(\sum_{m=0}^{\infty} \frac{(-\mu \chi)^{m}}{m !}\right) d \chi\right)\right\} \\
& \approx\left\{\left[\vartheta_{1} P T_{P}-\frac{\left(\vartheta_{1}-\vartheta_{2}\right) P \mu}{2}\left(T_{P}\right)^{2}\right]\right\}
\end{aligned}
$$


In this study, product quality is the responsibility of the manufacturer and should be reviewed periodically [36]. The frequent JIT deliveries enable nonconforming processes to be rapidly detected and addressed, thus, this reduces the number of nonconforming items. The decrease in number of nonconforming objects is expected to be related to the delivered material frequency. The cost of repair can be represented as:

$$
R_{C}=C_{R}\left[E(\phi)\left(1-\sum_{j=1}^{M} r_{j}\left(n_{j}-1\right)\right)\right]
$$

For the duration of its use (i.e., the warranty period), the hazard rates for conforming and nonconforming items are $v_{1}(\tau)$ and $v_{2}(\tau)$, respectively, and the mean failure rates are $h_{1}=\int_{0}^{K} v_{1}(\tau) d \tau$ and $h_{2}=\int_{0}^{K} v_{2}(\tau) d \tau$, respectively. The cost of the free-repair warranty is

$$
P O=C_{w}\left\{\left[E(\phi)\left(1-\sum_{j=1}^{M} r_{j}\left(n_{j}-1\right)\right)\right] h_{2}+\left[Q^{N}-\left(E(\phi)\left[1-\sum_{j=1}^{M} r_{j}\left(n_{j}-1\right)\right]\right)\right] h_{1}\right\}
$$

If the hazard rates of conforming and nonconforming products follow a Weibull distribution (please see [43]), then the mean failure rates are $h_{1}=\int_{0}^{K} v_{1}(\tau) d \tau=\int_{0}^{K}\left(\lambda_{1}^{\rho_{1}} \rho_{1} t^{\rho_{1}-1}\right) d t=\left(\lambda_{1} K\right)^{\rho_{1}}$ and $h_{2}=\int_{0}^{K} v_{2}(\tau) d \tau=\int_{0}^{K}\left(\lambda_{2}^{\rho_{2}} \rho_{2} t^{\rho_{2}-1}\right) d t=\left(\lambda_{2} K\right)^{\rho_{2}}$, respectively.

The post-sale warranty cost is derived as follows:

$$
\begin{aligned}
& P O=C_{w}\left\{\left[E(\phi)\left(1-\sum_{j=1}^{M} r_{j}\left(n_{j}-1\right)\right)\right]\left(h_{2}-h_{1}\right)+P T_{P} h_{1}\right\} \\
& =C_{w}\left\{\left[\left(\vartheta_{1} P T_{P}-\frac{\left(\vartheta_{1}-\vartheta_{2}\right) P \mu}{2}\left(T_{P}\right)^{2}\right)\left(1-\sum_{j=1}^{M} r_{j}\left(n_{j}-1\right)\right)\right]\left(h_{2}-h_{1}\right)+P T_{P} h_{1}\right\}
\end{aligned}
$$

\subsection{Material Cost}

From Figure 2, the inventory level for material $j$ can be expressed using the following differential equation:

$$
\frac{d \Psi_{m j}(t)}{d t}=-\alpha_{j} P-\theta \Psi_{m j}(t) 0 \leq t \leq T_{P} / n_{j}
$$

For the boundary condition $\Psi_{m j}\left(T_{P} / n_{j}\right)=0$, Equation (15) can be solved as follows:

$$
\Psi_{m j}(t)=\frac{\alpha_{j} P}{\theta}\left\{e^{\left[\theta\left(T_{P} / n_{j}-t\right)\right]}-1\right\}
$$

From Equation (2), $\Psi_{m j}(0)=Q^{N \prime}{ }_{m j}$, and assuming very small $\theta$, the delivery batch size can be determined as follows:

$$
Q^{N \prime}{ }_{m j}=\Psi_{m j}(0)=\frac{\alpha_{j} P}{\theta}\left\{e^{\left[\frac{\theta T_{P}}{n_{j}}\right]}-1\right\} \approx \alpha_{j} P \frac{T_{P}}{n_{j}}\left[1+\frac{\theta T_{P}}{2 n_{j}}\right]
$$

Additional handling costs include tax and overheads are given by:

$$
\sum_{j=1}^{M}\left[h_{d m j} \alpha_{j} n_{j}\left(\frac{P T_{P}}{n_{j}}\right)\left(1+\frac{\theta T_{P}}{2 n_{j}}\right)\right]
$$


The total storage cost for material $j$ is

$$
\begin{gathered}
H_{r j} n_{j} \int_{0}^{T_{P} / n_{j}} \Psi_{m j}\left(t_{j}\right) d t_{j}=H_{r j} n_{j} \int_{0}^{T_{P} / n_{j}} \frac{\alpha_{j} P}{\theta}\left\{\mathrm{e}^{\left[\theta\left(\frac{T_{P}}{n_{j}}-t_{j}\right)\right]}-1\right\} d t_{j} \\
=\frac{H_{r j} n_{j} \alpha_{j} P}{\theta} \cdot\left\{\frac{-1-\theta T_{P} / n_{j}+e^{\left(\theta T_{P} / n_{j}\right)}}{\theta}\right\}
\end{gathered}
$$

The total profit for the manufacturer can be written as follows:

$$
\begin{gathered}
\frac{\left(C_{P}-G_{m}\right)}{1-\theta}\left\{\mu_{c}+\frac{\sigma\left(\frac{R}{Z}\right)}{\left[1-\left(\frac{R}{Z}\right)^{2}\right]^{\frac{1}{2}}}\right\}=\sum_{j=1}^{M}\left[h_{d m j} \frac{\alpha_{j} n_{j} P}{\theta}\left[\mathrm{e}^{\left(\frac{P T_{P}}{n_{j}}\right)}-1\right]\right] \\
+\left\{\sum _ { j = 1 } ^ { M } \left[n_{j} C_{m j}+\frac{n_{j} g_{1 j}}{\theta} \cdot\left\{\frac{-1-\theta T_{P} / n_{j}+\mathrm{e}^{\left(\theta T_{P} / n_{j}\right)}}{\theta}\right\}+\frac{n_{j} g_{2 j}}{\theta}\left\{\mathrm{e}^{\left[\frac{\theta T_{P}}{n_{j}}\right]}-1\right\}\right.\right. \\
\left.\times\left(g_{3 j}+\frac{g_{4 j} T_{P}}{2}\right)\right]+C_{S}+\frac{H P\left[\theta T_{P}-1+\mathrm{e}^{\left.-\theta T_{P}\right]}\right.}{\theta^{2}} \\
+\left[g_{5}\left(1-\sum_{j=1}^{M} r_{j}\left(n_{j}-1\right)\right)+g_{7}\right] T_{P} \\
\left.-g_{6}\left(1-\sum_{j=1}^{M} r_{j}\left(n_{j}-1\right)\right) T_{P}^{2}\right\}
\end{gathered}
$$

This problem is equivalent to the following minimization problem:

Minimize $T P_{G}(\underline{n})=$

$$
\begin{gathered}
\sum_{j=1}^{M}\left[h_{d m j} \frac{\alpha_{j} n_{j} P}{\theta}\left[\mathrm{e}^{\left(\frac{P T_{P}}{n_{j}}\right)}-1\right]\right]+\left\{\sum _ { j = 1 } ^ { M } \left[n_{j} C_{m j}+\frac{n_{j} g_{1 j}}{\theta} \cdot\left\{\frac{-1-\theta T_{P} / n_{j}+\mathrm{e}^{\left(\theta T_{P} / n_{j}\right)}}{\theta}\right\}\right.\right. \\
\left.+\frac{n_{j} g_{2 j}}{\theta}\left\{\mathrm{e}^{\left[\frac{\theta T_{P}}{n_{j}}\right]}-1\right\} \times\left(g_{3 j}+\frac{g_{4 j} T_{P}}{2}\right)\right]+C_{S}+\frac{H P\left[\theta T_{P}-1+\mathrm{e}^{\left(-\theta T_{P}\right)}\right]}{\theta^{2}} \\
\left.+\left[g_{5}\left(1-\sum_{j=1}^{M} r_{j}\left(n_{j}-1\right)\right)+g_{7}\right] T_{P}-g_{6}\left(1-\sum_{j=1}^{M} r_{j}\left(n_{j}-1\right)\right) T_{P}^{2}\right\}
\end{gathered}
$$

where $\underline{n}=\left(n_{1}, n_{2}, \ldots, n_{M}\right), g_{1 j}=\alpha_{j} P H_{r j}, g_{2 j}=\alpha_{j} P, g_{3 j}=L^{1}{ }_{j}\left(C_{r j}+H_{r j}\right)+C_{r j}$,

$$
\begin{gathered}
g_{4 j}=\left(C_{r j}+H_{r j}\right), j=(1,2, \ldots, M), g_{6}=\left[\frac{\left[C_{w}\left(h_{2}-h_{1}\right)+C_{R}\right]\left(\vartheta_{1}-\vartheta_{2}\right) P \mu}{2}\right] \\
g_{7}=\left\{C_{w} P h_{1}+\mu P\right\}, g_{5}=\left(\vartheta_{1} P\right)\left(C_{R}+C_{w}\left(h_{2}-h_{1}\right)\right) \\
\text { and } T_{P}=\frac{1}{\theta}\left\{1-\sqrt{1-\frac{2 \theta Q^{N}}{P(1-\theta)}}\right\}
\end{gathered}
$$

The value of $g_{1 j}$ is determined based on the material storage cost for material $j, g_{2 j}$ is determined based on the production cost, $g_{3 j}$ is determined based on the unit cost of the material $j, g_{4 j}$ is determined based on the storage cost rate of the material $j, g_{5}$ is determined by the repair cost, and $g_{6}$ is determined by the post-sale warranty cost.

\section{Theoretical Derivations}

To maximize the supply chain profit, the optimal wholesale price $\left(C_{P}^{*}\right)$ for the manufacturer and the optimal replenishment quantity for materials $\underline{n}^{*}$ must be regulated. The optimal ordering decisions are determined by the retailer. Suppose that $T P_{G j}\left(n_{j}\right)$ represents the total profit for a single material; the replenishment quantity $\underline{n^{*}}$ can then be determined by minimizing $T P_{G}(\underline{n})$. 


\section{Property 1.}

$$
\begin{gathered}
\text { If }\left(C_{m j}+g_{6} r_{j} T_{P}^{2}\right)>g_{5} r_{j} T_{P} \text {, then there exists } n_{j}^{*} \text { such that } \\
n_{j}^{*}\left(n_{j}^{*}-1\right) \leq \frac{\left\{\left[g_{1 j}+\theta\left(h_{d m j} P+g_{2 j}\left(g_{4 j} T_{P} / 4+g_{3 j} / 2\right)\right)\right]\right\}}{2\left[C_{m j}-r_{j} T_{P}\left(g_{5}-g_{6} T_{P}\right)\right]} \cdot T_{P}^{2} \leq n_{j}^{*}\left(n_{j}^{*}+1\right), \\
\text { where } j=1 \ldots \ldots \text { Mand } T P_{G}\left(n_{1}^{*}-1, n_{2}^{*}-1, \ldots, n_{M}^{*}-1, C_{P}\right) \geq T P_{G}\left(n_{1}^{*}, n_{2}^{*}, \ldots, n_{M^{\prime}}^{*} C_{P}\right) \\
\leq T_{G}\left(n_{1}^{*}+1, n_{2}^{*}+1, \ldots, n_{M}^{*}+1, C_{P}\right)
\end{gathered}
$$

Proof. $T P_{G}(\underline{n})$ is estimated using the Taylor expansion after neglecting the exponential terms of order higher than two.

Choose $n_{j}=n_{j}^{*}, j=1 \ldots \ldots M$, such that

$$
T P_{G}\left(n_{1}^{*}-1, n_{2}^{*}-1, \ldots, n_{M}^{*}-1\right) \geq T P_{G}\left(n_{1}^{*}, n_{2}^{*}, \ldots, n_{M}^{*}\right) \leq T P_{G}\left(n_{1}^{*}+1, n_{2}^{*}+1, \ldots, n_{M}^{*}+1\right)
$$

Because $n_{i}$ does not depend on $n_{j}$ for $i \neq j$ and $n_{j}$ is independent of $C_{P}$, then $\underline{n^{*}}$ can be derived. For the total profit for material $j, T P_{G S j}\left(n_{j}\right)$ the following relationships hold:

$$
\begin{gathered}
T P_{G S 1}\left(n_{1}^{*}-1\right) \geq T P_{G S 1}\left(n_{1}^{*}\right) \leq T P_{G S 1}\left(n_{1}^{*}+1\right) \\
\operatorname{TP}_{G S 2}\left(n_{2}^{*}-1\right) \geq T P_{G S 2}\left(n_{2}^{*}\right) \leq T P_{G S 2}\left(n_{2}^{*}+1\right) \\
T P_{G S M}\left(n_{M}^{*}-1\right) \geq T P_{G S M}\left(n_{M}^{*}\right) \leq T P_{G S M}\left(n_{M}^{*}+1\right)
\end{gathered}
$$

The necessary condition for the optimal solution is given as follows:

$$
n_{j}^{*}\left(n_{j}^{*}-1\right) \leq \frac{\left\{\left[g_{1 j}+\theta\left(h_{d m j} P+g_{2 j}\left(g_{4 j} T_{P} / 4+g_{3 j} / 2\right)\right)\right]\right\}}{2\left[C_{m j}-r_{j} T_{P}\left(g_{5}-g_{6} T_{P}\right)\right]} \cdot T_{P}^{2} \leq n_{j}^{*}\left(n_{j}^{*}+1\right)
$$

where $j=1 \ldots \ldots$.

Based on Equation (21), when $C_{m j}-r_{j} T_{P}\left(g_{5}-g_{6} T_{P}\right)>0$, the necessary condition is found. The repair cost, the post-sale warranty cost, and the material ordering cost affect the material delivery decision.

Property 2. As the deterioration rate tends to zero, the optimal number of deliveries for material $j$ is given by

$$
n_{j}\left(n_{j}-1\right) \leq \frac{g_{1 j}}{2\left[C_{m j}-r_{j} T_{P}\left(g_{5}-g_{6} T_{P}\right)\right]} \cdot T_{P}^{2} \leq n_{j}\left(n_{j}+1\right)
$$

Proof. When $\theta=0$ is substituted into (21c), then $\theta\left(h_{d m j} P+g_{2 j}\left(g_{4 j} T_{P} / 4+g_{3 j} / 2\right)\right) \rightarrow 0$ and, consequently, we get $n_{j}\left(n_{j}-1\right) \leq \frac{g_{1 j}}{2\left[C_{m j}-r_{j} T_{P}\left(g_{5}-g_{6} T_{P}\right)\right]} \cdot T_{P}^{2} \leq n_{j}\left(n_{j}+1\right)$ which completes the proof.

Property 2 indicates that the ordering cost, production rate, storage cost rate, repair cost, and warranty cost influence delivery decision making. 


\subsection{The Sufficient Condition}

When the Hessian matrix $\nabla^{2} T P_{G}(\underline{n})$ is positive definite, a sufficient condition for optimality is achieved. Based on the property of $\partial^{2} T P_{G}(\underline{n}) / \partial n_{i} \partial n_{j}=0, i \neq j$ (Appendix B), the Hessian matrix can be easily obtained. When the optimal points $\underline{n^{*}}=\left(n_{1}^{*}, n_{2}^{*}, \ldots, n_{M}^{*}\right)$ are substituted into $T P_{G}(\underline{n})$, the optimal wholesale price $C_{P}^{*}$ can be established under a given profit, as follows:

$$
Q^{N *} \cdot G_{m}=Q^{N *} \cdot C_{P}-T P_{G}\left(\underline{n^{*}}\right)
$$

\subsection{Algorithm}

Due to the complexity of the total profit model, a heuristic algorithm procedure is proposed to obtain the optimal values.

Step 1: Input all of the related values.

Step 2: When the condition $\left(C_{m j}+g_{6} r_{j} T_{P}^{2}\right)>g_{5} r_{j} T_{P}$ is satisfied, there exists $n_{j}^{*}$ for each material; if this condition holds, proceed to Step 3; otherwise, proceed to Step 7.

Step 3: Check $n_{j}^{*}\left(n_{j}^{*}-1\right) \leq \frac{\left\{\left[g_{1 j}+\theta\left(h_{d m j} P+g_{2 j}\left(g_{4 j} T_{P} / 4+g_{3 j} / 2\right)\right)\right]\right\}}{2\left[C_{m j}-r_{j} T_{P}\left(g_{5}-g_{6} T_{P}\right)\right]} \cdot T_{P}^{2} \leq n_{j}^{*}\left(n_{j}^{*}+1\right)$ where $j=1 \ldots M$ to determine the optimal value of $n_{j}^{*}$.

Step 4: When $n_{j}^{*} j=1 \ldots M$ fulfills the sufficient condition for the optimal result, then $\underline{n^{*}}=\left(n_{1}^{*}, n_{2}^{*}, \ldots, n_{M}^{*}\right)$ is the optimal result; otherwise, proceed to Step 7 .

Step 5: The production lot size can be determined from $Q^{N *}=\frac{1}{1-\theta}\left\{\mu_{c}+\frac{\sigma(R / z)}{\left[1-(R / z)^{2}\right]^{1 / 2}}\right\}$, where $\frac{R}{Z}=\frac{L_{3}-L_{2}-L_{1}-2\left(L_{4}+L_{5}\right)}{L_{3}+L_{2}+L_{1}}$.

Step 6: The total cost is determined from Equation (20b), and $C_{P}$ is calculated from Equation (20a). Step 7: End.

\section{Numerical Examples and Discussion}

The preceding theoretical development is verified through the numerical examples.

Scenario 1: Assume a constant deterioration rate

On the basis of the inputs listed in Table 2, the optimal solution is shown in Table 3.

Table 2. Numerical examples.

\begin{tabular}{ccc}
\hline Parameters & Example $\mathbf{1}$ & Example 2 \\
\hline$\mu_{c}$ & 700 & 800 \\
$\sigma$ & 60 & 70 \\
$L_{1}$ & 0.64 & 0.64 \\
$L_{2}$ & 0.6 & 0.6 \\
$L_{3}$ & 0.58 & 0.58 \\
$L_{4}$ & 0.04 & 0.04 \\
$L_{5}$ & 0.05 & 0.05 \\
$C_{S}$ & 1200 & 1000 \\
$P$ & 1200 & 1200 \\
$\theta$ & 0.01 & 0.01 \\
$\mu$ & 0.015 & 0.015 \\
$K$ & 2 & 2 \\
$\lambda_{1}$ & 0.01 & 0.01 \\
$\lambda_{2}$ & 0.015 & 0.012 \\
$\rho_{1}$ & 0.8 & 0.8 \\
$\rho_{2}$ & 0.9 & 0.8 \\
\hline
\end{tabular}


Table 2. Cont.

\begin{tabular}{ccc}
\hline Parameters & Example 1 & Example 2 \\
\hline$A_{0}$ & 230 & 230 \\
$F$ & 600 & 600 \\
$\vartheta_{1}$ & $1 / 320$ & $1 / 360$ \\
$\vartheta_{2}$ & $1 / 220$ & $1 / 240$ \\
$C_{R}$ & 40 & 40 \\
$C_{w}$ & 100 & 90 \\
$G_{m}$ & 25 & 25 \\
$u$ & 2 & 2 \\
$H$ & 4 & 4.5 \\
$L_{1}^{1}$ & 0.002 & 0.0027 \\
$L_{2}^{1}$ & & 0.0025 \\
$C_{m 1}$ & 285 & 300 \\
$C_{m 2}$ & & 310 \\
$h_{d m 1}$ & 13 & 10 \\
$h_{d m 2}$ & & 13 \\
$C_{r 1}$ & 5 & 4 \\
$C_{r 2}$ & & 4.6 \\
$H_{r 1}$ & 3.5 & 3 \\
$H_{r 2}$ & & 4 \\
$\alpha_{1}$ & 3 & 2 \\
$\alpha_{2}$ & & 3 \\
$r_{1}$ & 0.0015 & 0.001 \\
$r_{2}$ & & 0.001 \\
\hline & &
\end{tabular}

Table 3. Optimal solutions of the numerical examples.

\begin{tabular}{lccc}
\hline & Value of $n^{*}$ & Value of $C_{\boldsymbol{P}}^{*}$ & Total cost $\mathbf{T P}_{\boldsymbol{G}}\left(\underline{\boldsymbol{n}}^{*}\right)$ \\
\hline Example 1 & $n^{*}(\cong 2.68)=3$ & 59.74 & $23,397.27$ \\
\hline Example 2 & $\left(n_{1}^{*}, n_{2}^{*}\right) \cong(2.26,3.14)=(2,3)$ & 76.62 & $39,671.64$ \\
\hline
\end{tabular}

From the necessary condition stated in Property 1 , the optimal number of material deliveries is three and according to the Hessian matrix, the optimal total profit is 152.15. Therefore, this number of material deliveries is an optimal and unique solution. The optimal solution for multiple materials is also presented in Table 3. Multiple material deliveries incur a higher cost than a single delivery. However, the cost of purchase is also slightly increased. In practice, the smooth operation of a manufacturing site requires multiple material deliveries, and some losses must be incurred.

Scenario 2: Variable deterioration rate

For a variable deterioration rate, the optimal solution demonstrates that increases in the deterioration rate increase the optimal ordering quantity, selling price, total cost, and optimal number of material deliveries. This is because when the rate of deterioration is high, a considerable percentage of the products are lost, along with their related revenues. Table 4 lists various deterioration rates, and the associated changes to clarify the effect of deterioration on the total cost. This information can provide insight to management to restrict deterioration in order to secure a favorable profit margin. Table 4 and Figure 3 illustrate the optimal total cost solutions for various deterioration rates. 
Table 4. Optimal solutions for various deterioration rates.

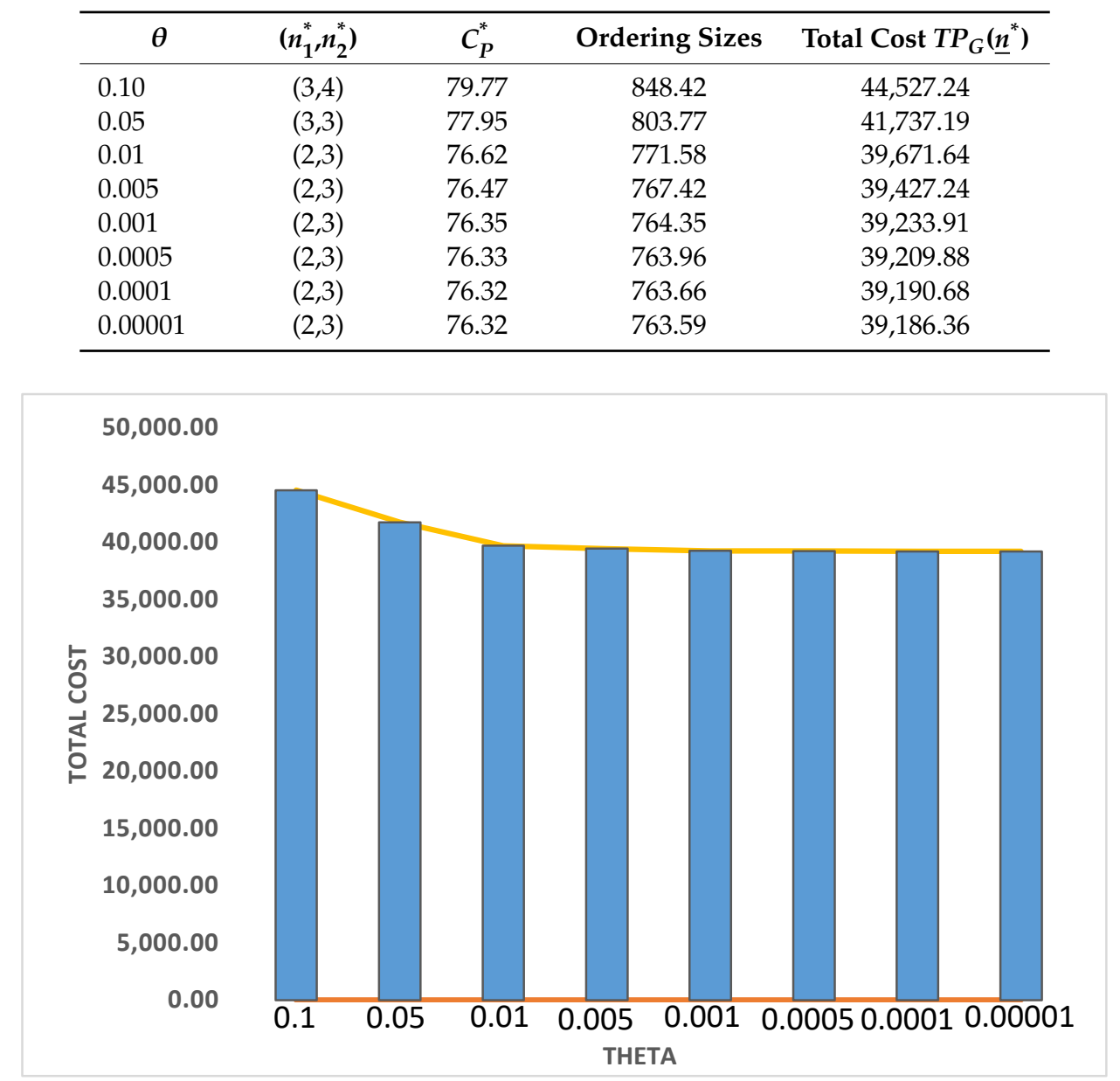

Figure 3. Total cost for various deterioration rates.

\section{Conclusions}

In this study, we propose a two-echelon distribution-free deteriorating production-inventory model for deteriorating products with imperfect processes. The proposed newsboy problem model not only incorporates product deterioration, but also JIT multiple deliveries. We have shown some interesting results for varying deteriorating rates in the numerical analysis. We have observed that any increase in deterioration rate raises the optimal ordering quantity, selling price, total cost, and optimal number of material deliveries. Moreover, the model also implemented JIT deliveries which enable rapid detection and rectification of the nonconforming items; this approach reduces the number of nonconforming items. In the study, the optimal ordering policies for the retailer are derived. The results of this study can provide some managerial insights for manufacturers and retailers in their decision making. Theoretical derivations are provided to demonstrate the concavity of the profit function. Besides the model development, a solution procedure is provided to assist manufacturers in determining the optimal wholesale price and replenishing cycle.

The limitations of the study ignore the environmental concerns and assume a single manufacturer-supplier. For the further research, this study can be extended to consider carbon footprint, multiple manufacturers, and multiple suppliers. One can also consider preservation technology to reduce the deterioration rate of the products.

Author Contributions: Conceptualization, A.H.M.M. and H.-M.W.; Methodology, A.H.M.M., C.-V.H., H.-M.W. and J.Z.W., Authentication, H.-M.W. and J.-Z.W.; Resources, H.-M.W., A.H.M.M. and C.-V.H.; Writing-Original Draft Preparation, A.H.M.M., H.-M.W. and J.-Z.W.; Writing-Review and Editing, A.H.M.M. and H.-M.W.; Supervision, H.-M.W. and J.-Z.W. All authors have read and agreed to the published version of the manuscript. 
Funding: The study was partially supported by the Ministry of Science and Technology, Taiwan (MOST108-2911-I-031-502; MOST108-2221-E-031-001-MY2) and the Center for Applied Artificial Intelligence Research, Soochow University, Taiwan (C-01).

Conflicts of Interest: The authors have no conflicts of interest to declare. The funders had no role in the design of the study; in the collection, analyses, or interpretation of the data; in the writing of the manuscript; or in the decision to publish.

\section{Appendix A}

From Equation (8), the square roots of the production time can be written as

$$
\begin{aligned}
& T_{P 1}=\frac{-2 P(1-\theta)+2 \sqrt{P^{2}(1-\theta)^{2}-2 P \theta Q(1-\theta)}}{2 P \theta(-1+\theta)}=\frac{g_{1}(\theta)}{F_{1}(\theta)} \\
& T_{P 2}=\frac{-2 P(1-\theta)-2 \sqrt{P^{2}(1-\theta)^{2}-2 P \theta Q(1-\theta)}}{2 P \theta(-1+\theta)}=\frac{g_{2}(\theta)}{F_{2}(\theta)}
\end{aligned}
$$

Let $g_{1}(\theta)=-2 P(1-\theta)+2 \sqrt{P^{2}(1-\theta)^{2}-2 P \theta Q(1-\theta)}$ and $F_{1}(\theta)=2 P \theta(-1+\theta)$; according to L’Hôspital's rule,

$$
\begin{gathered}
\lim _{\theta \rightarrow 0} T_{P 1}=\lim _{\theta \rightarrow 0} \frac{-2 P(1-\theta)+2 \sqrt{P^{2}(1-\theta)^{2}-2 P \theta Q(1-\theta)}}{2 P \theta(-1+\theta)}=\lim _{\theta \rightarrow 0} \frac{g_{1}(\theta)}{F_{1}(\theta)} \\
=\lim _{\theta \rightarrow 0} \frac{d g_{1}(\theta) / d \theta}{d F_{1}(\theta) / d \theta}=\frac{2 P+\frac{2 P^{2}(\theta-1)-2 P Q(1-2 \theta)}{\sqrt{P^{2}(1-\theta)^{2}-2 P \theta Q(1-\theta)}}}{-2 P+4 P \theta}=-1+1+\frac{Q}{P}=\frac{Q}{P}
\end{gathered}
$$

Similarly, let $g_{2}(\theta)=-2 P(1-\theta)-2 \sqrt{P^{2}(1-\theta)^{2}-2 P \theta Q(1-\theta)}$ and $F_{2}(\theta)=2 P \theta(-1+\theta)$; thus,

$$
\begin{gathered}
\lim _{\theta \rightarrow 0} T_{P 2}=\lim _{\theta \rightarrow 0} \frac{-2 P(1-\theta)-2 \sqrt{P^{2}(1-\theta)^{2}-2 P \theta Q(1-\theta)}}{2 P \theta(-1+\theta)}=\lim _{\theta \rightarrow 0} \frac{g_{2}(\theta)}{F_{2}(\theta)} \\
=\lim _{\theta \rightarrow 0} \frac{d g_{2}(\theta) / d \theta}{d F_{2}(\theta) / d \theta}=-1-1-\frac{Q^{N}}{\sqrt{P^{2}}}=-2+\frac{-Q^{N}}{P}
\end{gathered}
$$

We select Equation (A1) as the rational root of the production time.

\section{Appendix B}

The revised Hessian matrix is

$$
\nabla^{2} T P_{G}(\underline{n})=\left[\begin{array}{ccccc}
\frac{\partial^{2} T P_{G}}{\partial n_{1}^{2}} & 0 & 0 & \cdots & 0 \\
0 & \frac{\partial^{2} T P_{G}}{\partial n_{2}^{2}} & 0 & \cdots & 0 \\
0 & 0 & \ddots & \cdots & \vdots \\
\vdots & \vdots & \ldots & \frac{\partial^{2} T P_{G}}{\partial n_{M-1}^{2}} & 0 \\
0 & 0 & \ldots & 0 & \frac{\partial^{2} T P_{G}}{\partial n_{M}^{2}}
\end{array}\right]
$$

Because $\frac{\partial^{2} T P_{G}}{\partial n_{j}^{2}}>0$ and the matrix []$_{j \times j}$ are greater than zero, $\nabla^{2} T P_{G}(\underline{n})$ is positive definite. 


\section{References}

1. Bhuniya, S.; Sarkar, B.; Pareek, S. Multi-Product Production System with the Reduced Failure Rate and the Optimum Energy Consumption under Variable Demand. Mathematics 2019, 7, 465. [CrossRef]

2. Tayyab, M.; Sarkar, B.; Yahya, B. Imperfect Multi-Stage Lean Manufacturing System with Rework under Fuzzy Demand. Mathematics 2019, 7, 13. [CrossRef]

3. Mashud, A.H.M. A deteriorating inventory model with different types of demand and fully backlogged shortages. Int. J. Logis. Sys. Manag. 2020, 36, 16-45. [CrossRef]

4. Wee, H.M.; Kuo, T.C.; Huang, Y.D.; Lin, Y.J. Two-stage newsboy problem for fashion products considering revenue sharing and return policies. J. Indust. Prod. Eng. 2013, 30, 500-509. [CrossRef]

5. Yang, P.; Pai, S.; Yang, L.; Wee, H.M. Constrained optimization of newsboy problem with return policy. Appl. Mat. Inf. Sci. 2012, 6, 635-641.

6. Gallego, G.; Moon, I. The distribution-free newsboy problem-review and extensions. J. Oper. Res. Soc. 1993, 44, 734-825. [CrossRef]

7. Nagare, M.; Dutta, P.; Cheikhrouhou, N. Extended distribution-free newsvendor models with demand updates using experts' judgment. Int. Trans. Oper. Res. 2019. [CrossRef]

8. Kalpana, P.; Kaur, A. Single-period inventory models with multiple ordering opportunities: A review. Int. J. Logist. Syst. Manag. 2012, 13, 209-229. [CrossRef]

9. Moon, I.; Choi, S. Distribution free newsboy problem with balking. J. Oper. Res. Soc. 1995, 46, 537-542. [CrossRef]

10. Mashud, A.H.M.; Khan, M.A.-A.; Uddin, M.S.; Islam, M.N. A non-instantaneous inventory model having different deterioration rate with stock and price dependent demand under partially backlogged. Unce. Sup. Cha. Manag. 2018, 6, 49-64. [CrossRef]

11. Mashud, A.H.M.; Hasan, M.R.; Wee, H.M.; Daryanto, Y. Non-instantaneous deteriorating inventory model under the joined effect of trade-credit, preservation technology and advertisement policy. Kybernetes 2019, 49, 1645-1674. [CrossRef]

12. Mashud, A.H.M.; Wee, H.M.; Sarkar, B.; Chiang Li, Y.H. A sustainable inventory system with the advanced payment policy and trade-credit strategy for a two- warehouse inventory system. Kybernetes 2020. [CrossRef]

13. Mashud, A.H.M.; Wee, H.M.; Huang, C.V. Preservation technology investment, trade credit and partial backordering model for a non-instantaneous deteriorating inventory. RAIRO Oper. Res. 2019. (In press) [CrossRef]

14. Ghare, P.M.; Schrader, S.F. A model for exponentially decaying inventory. J. Ind. Eng. 1963, 14, $238-243$.

15. Covert, R.P.; Philip, G.C. An EOQ model for items with Weibull distribution deterioration. AIIE Trans. 1973, 5, 323-326. [CrossRef]

16. Raafat, F.; Wolfe, P.M.; Eldin, H.K. An inventory model for deteriorating items. Comput. Ind. Eng. 1991, 20, 89-94. [CrossRef]

17. Wee, H.M. Economic production lot size model for deteriorating items with partial back-ordering. Comput. Ind. Eng. 1993, 24, 449-458. [CrossRef]

18. Wee, H.M.; Jong, J.F. An integrated multi-lot-size production inventory model for deteriorating items. Manag. Syst. 1998, 5, 97-114.

19. Perez, F.; Torres, F. An integrated production-inventory model for deteriorating items to evaluate JIT purchasing alliances. Int. J. Ind. Eng. Comput. 2019, 10, 51-66. [CrossRef]

20. Yang, P.C.; Wee, H.M. An integrated multi-lot-size production inventory model for deteriorating item. Comput. Oper. Res. 2003, 30, 671-682. [CrossRef]

21. Lau, A.H.L.; Lau, H.S. The effects of reducing demand uncertainty in a manufacturer-retailer channel for single-period products. Comput. Oper. Res. 2002, 29, 1583-1602.

22. Lariviere, M.; Porteus, E.L. Selling to the newsvendor: An analysis of price-only contracts. Manuf. Serv. Op. Manag. 2001, 3, 293-305. [CrossRef]

23. Malek, L.L.A.; Ziegler, H. Age dependent perishability in two-echelon serial inventory systems. Comput. Oper. Res. 1988, 15, 227-239. [CrossRef]

24. Yoo, S.H.; Kim, D.; Park, M.S. Economic production quantity model with imperfect-quality items, two-way imperfect inspection and sales return. Int. J. Prod. Econ. 2009, 121, 255-265. [CrossRef] 
25. Sarkar, B.; Ullah, M.; Kim, N. Environmental and economic assessment of closed-loop supply chain with remanufacturing and returnable transport items. Comput. Ind. Eng. 2017, 111, 148-163. [CrossRef]

26. Eppen, G.D. Effect of centralization on expected costs in a multi-location newsboy problem. Manag. Sci. 1979, 25, 498-503. [CrossRef]

27. Alfares, H.K.; Elmorra, H.H. The distribution-free newsboy problem: Extensions to the shortage penalty case. Int. J. Prod. Econ. 2005, 93-94, 465-477. [CrossRef]

28. Cherikh, M. On the effect of centralization on expected profits in a multi-location newsboy problem. J. Oper. Res. Soc. 2000, 51, 755-761. [CrossRef]

29. Choi, T.M.; Li, D.; Yan, H. Optimal two-stage ordering policy with Bayesian information updating. J. Oper. Res. Soc. 2003, 54, 846-859. [CrossRef]

30. Dutta, P. A multi-product newsboy problem with fuzzy customer demand and a storage space constraint. Int. J. Oper. Res. 2010, 8, 230-246. [CrossRef]

31. Zhou, Y.W.; Wang, S.D. Manufacturer-buyer coordination for newsvendor products with two ordering opportunities and partial back orders. Eur. J. Oper. Res. 2009, 198, 958-974. [CrossRef]

32. Yu, Y.; Zhu, J.; Wang, C. A newsvendor model with fuzzy price-dependent demand. Appl. Math. Model. 2013, 37, 2644-2661. [CrossRef]

33. Rossi, R.; Prestwich, S.; Tarim, S.A.; Hnich, B. Confidence-based optimization for the newsvendor problem under binomial, Poisson and exponential demand. Eur. J. Oper. Res. 2014, 239, 674-684. [CrossRef]

34. Dutta, P.; Chakraborty, D. Incorporating one-way substitution policy into the newsboy problem with imprecise customer demand. Eur. J. Oper. Res. 2010, 200, 99-110. [CrossRef]

35. Sakakibara, S.; Flynn, B.; Schroeder, R.; Morris, W. The impact of Just-in-Time manufacturing and its infrastructure on manufacturing performance. Manag. Sci. 1997, 43, 1246-1257. [CrossRef]

36. Nassimbeni, G. Factors underlying operational purchasing practices: Results of a research. Int. J. Prod. Econ. 1995, 42, 275-288. [CrossRef]

37. Reese, J.; Geisel, R. A comparison of current practice in German manufacturing industries. Eur. J. Purch. Supply. Manag. 1997, 42, 275-288. [CrossRef]

38. Gunasekaran, A. Just-in-time purchasing: An investigation for research and application. Int. J. Prod. Econ. 1999, 59, 77-84. [CrossRef]

39. Batrancea, I.; Rathnaswamy Malar, M.; Gaban, L.; Fatacean, G.; Tulai, H.; Bircea, I.; Rus, M.I. An Empirical Investigation on Determinants of Sustainable Economic Growth. Lessons from Central and Eastern European Countries. J. Ris. Fin. Manag. 2020, 13, 146. [CrossRef]

40. Batrancea, I.; Rathnaswamy Malar, M.; Batrancea, L.; Nichita, A.; Gaban, L.; Fatacean, G.; Tulai, H.; Bircea, I.; Rus, M.I. A Panel Data Analysis on Sustainable Economic Growth in India, Brazil, and Romania. J. Ris. Fin. Manag. 2020, 13, 170. [CrossRef]

41. Larissa, B.; Maran, R.M.; Ioan, B.; Anca, N.; Mircea-Iosif, R.; Horia, T.; Gheorghe, F.; Ema Speranta, M.; Dan, M.I. Adjusted Net Savings of CEE and Baltic Nations in the Context of Sustainable Economic Growth: A Panel Data Analysis. Ris. Fin. Manag. 2020, 13, 234.

42. Batrancea, I.; Batrancea, L.; Nichita, A.; Gaban, L.; Masca, E.; Fatacean, G.; Moscviciov, A. An econometric approach on production, costs and profit in Romanian coal mining enterprises. Eco. Rese. 2019, 32, 1019-1036. [CrossRef]

43. Kung, K.Y.; Huang, Y.D.; Wee, H.M.; Daryanto, Y. Production-inventory system for deteriorating items with machine breakdown, inspection and partial backordering. Mathematics 2019, 7, 616. [CrossRef]

44. Hsu, J.T.; Hsu, L.F. An EOQ model with imperfect quality items, inspection errors, shortage backordering, and sales returns. Int. J. Prod. Econ. 2013, 143, 162-170. [CrossRef]

45. Salameh, M.K.; Jaber, M.Y. Economic production quantity model for items with imperfect quality. Int. J. Prod. Econ. 2000, 64, 59-64. [CrossRef]

46. Lee, H.L.; Rosenblatt, M.J. Simultaneous determination of production cycle and inspection schedules in a production system. Manag. Sci. 1987, 33, 1125-1136. [CrossRef]

47. Hota, S.K.; Sarkar, B.; Ghosh, S.K. Effects of unequal lot size and variable transportation in unreliable supply chain management. Mathematics 2020, 8, 357. [CrossRef]

48. Daryanto, Y.; Wee, H.M.; Widyadana, G.A. Low Carbon Supply Chain Coordination for Imperfect Quality Deteriorating Items. Mathematics 2019, 7, 234. [CrossRef] 
49. Daryanto, Y.; Wee, H.M. Low carbon economic production quantity model for imperfect quality deteriorating items. Int. J. Ind. Eng. Eng. Manag. 2019, 1, 1-8. [CrossRef]

50. Shaw, B.K.; Sangal, I.; Sarkar, B. Joint Effects of Carbon Emission, Deterioration, and Multi-Stage Inspection Policy in an Integrated Inventory Model. In Optimization and Inventory Management; Springer Nature: Singapore, 2020; pp. 195-208. [CrossRef]

51. Hasan, R.; Mashud, A.H.M.; Daryanto, Y.; Wee, H.M. A non-instantaneous inventory model of agricultural products considering deteriorating impacts and pricing policies. Kybernetes 2020. [CrossRef]

52. Yeh, R.H.; Ho, W.T.; Teng, S.T. Optimal production run length for products sold with warranty. Eur. J. Oper. Res. 2000, 120, 575-582. [CrossRef]

53. Wang, C.H.; Sheu, S.H. Optimal lot size for products under free-repair warranty. Eur. J. Oper. Res. 2003, 149, 131-141. [CrossRef]

54. Wang, C.H. The impact of a free-repair warranty policy on EMQ model for imperfect production system. Comput. Oper. Res. 2004, 31, 2021-2035. [CrossRef]

55. Lin, T.Y. Effect of warranty and quantity discounts on a deteriorating production system with a Markovian production process and allowable shortages. J. Ind. Manag. Optim. 2017, 13. [CrossRef]

56. Ullah, M.; Khan, I.; Sarkar, B. Dynamic Pricing in a Multi-Period Newsvendor Under Stochastic Price-Dependent Demand. Mathematics 2019, 7, 520. [CrossRef]

57. Chung, J.C.; Wee, H.M. An integrated production-inventory deteriorating model for pricing policy considering imperfect production, inspection planning and warranty-period- and stock-level-dependent demand. Int. J. Syst. Sci. 2008, 39, 823-837. [CrossRef]

58. Spiegel, M.R. Applied Differential Equations; Prentice-Hall: Englewood Cliffs, NJ, USA, 1960.

Publisher's Note: MDPI stays neutral with regard to jurisdictional claims in published maps and institutional affiliations. 